\title{
ORGANIZED PHYSICAL ACTIVITY AND HEALTH IN PRESCHOOL AGE: A REVIEW
}

\author{
Fotini Venetsanou ${ }^{1}$, Antonis Kambas ${ }^{2}$, Dimitra Giannakidou ${ }^{2}$ \\ ${ }^{1}$ Faculty of Physical Education and Sport Science, University of Athens, Athens, Greece \\ ${ }^{2}$ Faculty of Physical Education and Sport Science, Democritus University of Thrace, Komotini, Greece
}

\section{SUMMARY}

Aim: The aim of this study was to investigate how organized Physical Activity (OPA) can contribute to the promotion of preschool aged children's health and specifically to health indicators such as adiposity, bone and skeletal health, cardiometabolic health, motor skill development, cognitive development, and psychosocial health.

Methods: A literature search of interventions aimed at improving health in preschool age was conducted in five electronic databases. Included in the review were only studies meeting the following criteria: published or accepted for publication studies; written in English; intervention with any type of oPA; 2-6 years old participants; pre- and post-objective assessments of the intervention effects; presence of a control group.

Results: The majority of studies that met the inclusion criteria $(n=13)$ considered the effect of oPA on children's motor development, while limited were those which examined the rest of the health indicators - adiposity $(n=4)$, bone and skeletal health $(n=2)$, cardiometabolic health $(n=0)$, cognitive development $(n=2)$, and psychosocial health $(n=4)$.

Conclusions: The information about how oPA can influence preschoolers' health status, although promising in most cases, was deficient. Questions about the kind, intensity, amount or frequency of physical activity (PA) required so as children's health to be enhanced still remain. Further research into the relationship between OPA and health in preschool age is required in order to draw conclusions enabling the development of efficient PA programmes to promote children's health.

Key words: physical activity, health status, exercise, early interventions, children

Address for correspondence: F. Venetsanou, Faculty of Physical Education and Sport Science, University of Athens, Ethnikis Antistasis 41, Dafni 17237, Athens, Greece. E-mail: fvenetsanou@phed.uoa.gr

\section{INTRODUCTION}

Nowadays obesity is one of the most serious risks for children's health, reaching epidemic levels (1). This rise in childhood obesity in the developed world, as well as the problems it bears, has turned the attention of researchers towards the detection of the root causes of the phenomenon, and the pursuit of the best practices for its avoidance.

However, until a few years ago, the lion's share of the research had focused on childhood and adolescence, while little attention had been paid to younger children's needs. The reason for that may have been the common belief that preschool age is a period during which children are usually active and consequently healthy. Nonetheless, the World Health Organization (2) estimates that more than 42 million preschool aged children are overweight, while several researchers report on the low physical activity levels and high sedentary ones for that specific age $(3,4)$.

The first years in human beings' life constitute a critical period for both their development (5) and the formation of physically active behaviours (6). Taking the above into consideration the need for the increase of preschoolers' physical activity (PA) as well as the planning of appropriate physical exercise programmes becomes imperative. According to WHO (2), an important public health message should be the idea of PA "investment". However, nowadays, when spontaneous PA is reduced and sedentary behaviours are increased (7) the promotion of organized developmen- tally appropriate PA programmes seems to be necessary in order for that "investment" to be accomplished.

The present study aims at investigating how organized PA (oPA) can contribute to the promotion of preschool children's health. For that purpose, health indicators that are of priority in that specific age and are presented by Tremblay et al. (8) have been adopted. Those indicators were the following: adiposity, bone and skeletal health, cardiometabolic health, motor skill development, cognitive development, and psychosocial health.

\section{MATERIALS AND METHODS}

A literature search of interventions to improve health in preschool age was performed in the MEDLINE, PsycINFO, SportDiscus, Scopus, and Google electronic databases. In order to include all possible relevant published studies, no date range was specified.

Search was conducted combining terms of three central key elements: preschool age (key words: preschool, kindergarten, young children); oPA (key words: physical activity, exercise, intervention, programme); health (key words: motor/movement skills, motor proficiency, motor development, coordination, health, bone, skeletal structure, adiposity, body mass index, obesity, body fat, psychosocial health, social competence, self esteem, social skills, cognitive development, language). Key terms referring to health 
were combined with "or" as was the case with terms relating to organized physical activity. Then, the results of the grouped searches for health and PA were combined with "and" so as to have papers related to the effect of PA interventions on children's health. Reference lists of the articles were also manually searched.

Included in the review were only studies meeting the following criteria: published or accepted for publication studies; written in English; intervention with any type of oPA; 2-6 years old participants; pre- and post-objective assessments of the intervention effects; presence of a control group (CG). For the purpose of the study, as CGs were defined children who engaged only in free play and/or continued to receive the typical kindergarten curriculum.

Several studies cited in the present paper presented major outcome measures other than those relevant to the aim of this project. These outcomes are described either briefly or not at all.

\section{RESULTS}

The database searches revealed a total of 1,473 potentially relevant articles. Screening of titles and abstracts reduced that list to 74 articles. All of them were reviewed, including their reference lists and 22 intervention studies meeting the inclusion criteria were identified.

The included studies involved 3,644 participants among 3-8 years of age. The interventions lasted from 6 weeks to 8 months and covered various types of PA. One study compared two different intervention programmes vs control. Regarding the health indicators studied, four articles reported on the effect of an intervention on adiposity, three on bone and skeletal health, zero on cardiometabolic health, 12 on motor skill development, two on cognitive development, and four on psychosocial health (Table 1).

\section{Review of oPA Effect on Preschoolers' Health Adiposity}

Obesity is determined by multiple interactions among human genes (9) and environment (10). Among those risk factors, diet and PA seem to be very important (14). Regarding PA, both cross-sectional and longitudinal studies have showed its strong relationship with children's body mass index (BMI) (11-13).

However, the findings of studies examining the effect of oPA on children's adiposity are poor and in some cases conflicting. Mosuwan et al. (14) evaluated the effect of an exercise programme on the obesity measures (BMI and triceps skinfold thickness) of 292 second grade elementary pupils. The experimental group (EG) of this study participated in an exercise programme that was conducted three times per week and comprised two parts: a 15 minute morning walk and an afternoon aerobic dance session lasting 20 minutes. The children of CG, on the other hand, continued their regular PA programme. After the implementation of the programme for 29.6 weeks, it was found that the exercise group reduced the prevalence of obesity indexes more than the control one; however, the difference between those two groups was not significant. Moreover, girls were found to respond to the exercise programme differently compared to boys, having reduced the likelihood of revealing an increased BMI by $68 \%$. The authors attributed that finding to the probable stricter following of the exercise programme by girls compared to boys and to the fact that girls are usually less physically active, and consequently the implemented intervention had a significant effect on their energy expenditure.

Similarly poor were the findings of Reilly et al. (15) who assessed the effect of a PA intervention on the BMI of 545 preschoolers in Scotland. The intervention consisted of a 24 weeks PA programme in nursery (three 30-minute sessions per week) and health education conducted at the participants' home aiming at increasing PA through play and decreasing sedentary behaviour. At the same time, CG continued with their usual curriculum. Both experimental and CG's BMI was assessed six and twelve months after the beginning of the intervention but no significant results on the reduction of children's BMI was displayed. Reilly et al. (15) thought that perhaps their intervention was not adequate enough to change children's BMI.

Inconsistent with each other were the results of the two studies of Fitzgibbon et al. $(16,17)$, who examined the impact of a dietary/PA intervention (Hip-Hop to Health Jr.) on changes in BMI of preschool minority children. Both interventions lasted 14 weeks each and included three 40-minute sessions per week with two components: healthy eating or PA education and aerobic activities. Moreover, parents were weekly informed about their children's curriculum and completed homework assignments. CG received a general health intervention not addressing diet or PA. Measures for both studies were conducted at baseline, post intervention, and at years 1 and 2 follow-up. In their first study (17), 289 Afro-American children aged 3-5 participated. According to their results, EG presented significantly smaller increases in BMI compared with the controls both at 1- and 2-year follow-ups. The researchers concluded that Hip-Hop to Health Jr. may be an effective approach for obesity prevention in preschool aged minority children. Nevertheless, the results of their second study (16) in which 331 Latino children participated were null. No differences were found in children's BMI at either post-intervention, year 1 or year 2 follow-ups, pinpointing that the programme was not effective for Latino children. The authors attributed this finding to cultural differences evoking different family practices on food, children's PA, parents' role as models for PA, etc.

\section{Bone and Skeletal Health}

In the last decades there is an increased prevalence of osteoporosis (18). The risk of that disease development seems to be influenced by the bone gain early in life (19) and PA is a major contributor to that (20).

The main body of literature regarding the impact of PA on preschoolers' bones comprised Specker et al. and Binkley et al. work (20-22). In their first paper (21), they tried to identify factors influencing bone features such as body bone area (TBBA) and total body bone mineral content (TBBMC) in 239 3-5 years old children. PA was among the factors examined but the results did not show a relationship between TBBMC or TBBA and PA. In the next step of their study (20), the aforementioned participants were randomly assigned to join a fine or gross motor programme for 12 months. Among them, 178 completed at least 38 weeks of the programme (in a 50 weeks total) and their data was presented. Each session lasted 30 minutes per day, five days per week. Moreover, in each group half children received calcium (1,000 mg/day) and the other half placebo. According to the results, there was a significant interaction between activity 


\begin{tabular}{|c|c|c|c|c|c|c|c|c|c|c|c|c|c|c|c|c|c|c|c|c|c|}
\hline 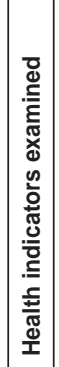 & 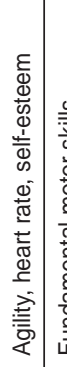 & 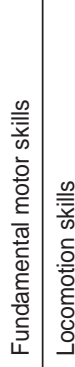 & 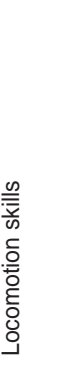 & 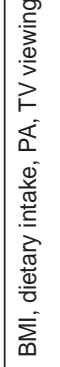 & 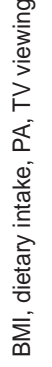 & 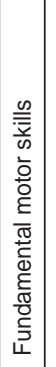 & 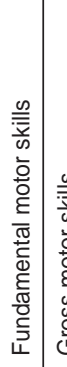 & 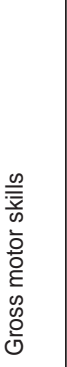 & 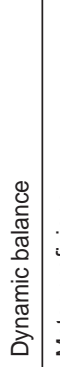 & 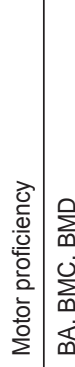 & 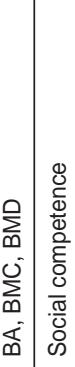 & 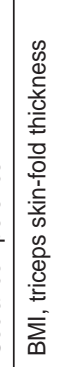 & 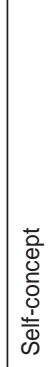 & 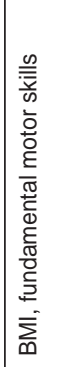 & 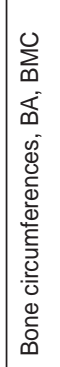 & 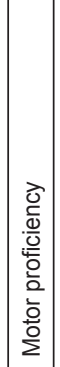 & 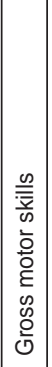 & 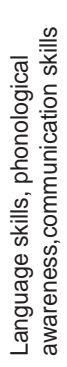 & 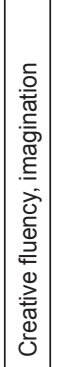 & 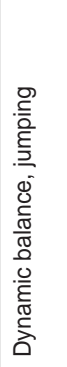 & 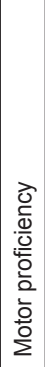 \\
\hline
\end{tabular}

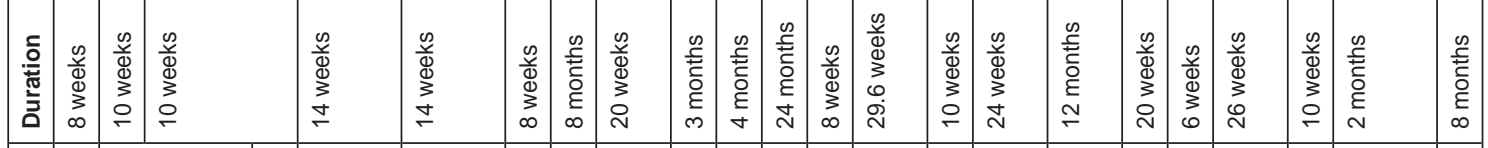

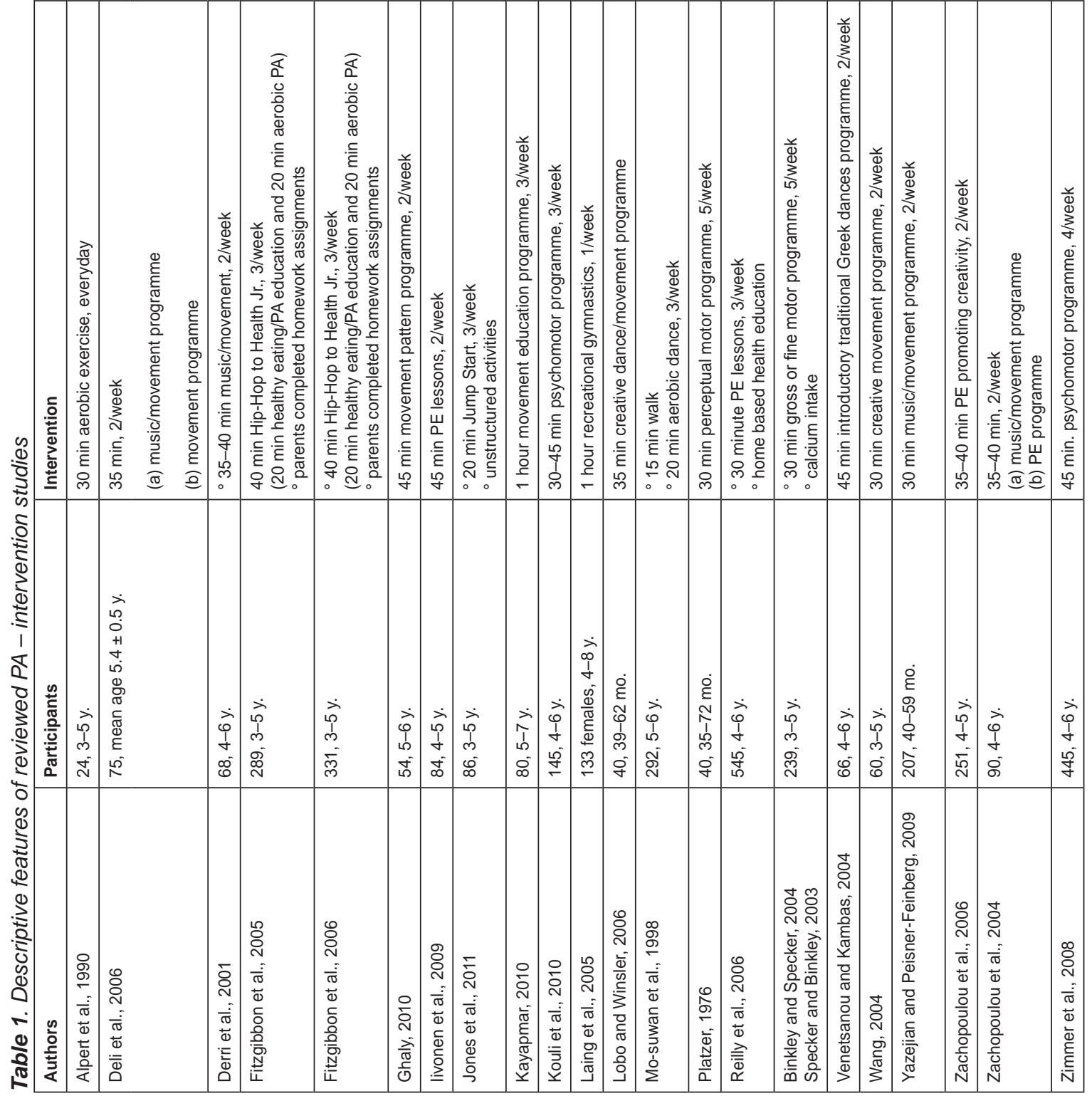


and supplement group in leg bone mineral content (BMC) gain with children receiving calcium and participating in gross motor activities to presenting greater gains. What is more, after the intervention, children of the gross motor group indicated greater periosteal and endosteal circumferences than those in the fine motor group irrespective of calcium intakes. Specker and Binkley (20) concluded that PA programmes stimulate bone growth in diameter and their combination with calcium intake culminates to a greater cortical thickness and area.

In 2004, Speckler and Binkley examined if the changes in leg bone mineral content and size caused by the aforementioned intervention were maintained 12 months after its end, by conducting follow-up measurement in 161 children from the sample of their previous study (20). The results revealed greater increases for arm bone area, total body and arm bone mineral content for the gross motor activity group, while there were no differences in bone area (BA) or BMC due to calcium intake. Furthermore, differences in tibia periosteal circumference found at the end of the intervention, persisted twelve months later with a tendency towards greater endosteal circumferences in the children of gross motor activities. It is worth mentioning that children of the gross motor group presented higher levels of PA than the fine motor group, six months after the end of the intervention. According to the authors (22), that may be the explanation for their greater gains in total body and arm BMC and arm BA, a finding absent at the end of the intervention.

Laing et al. (23) tried to identify whether the skeletal advantages presented in child gymnasts have already existed before their participation in gymnastics or are a result of it. For that purpose, changes in BA, BMC areal bone mineral density (aBMD) over 24 months were examined in 65 girls, 4-8 years of age, who chose to perform recreational gymnastics and 78 ones who preferred to participate either in non gymnastic activities or in no organized activity. Two years after the onset of the study, gymnasts had greater mean responses for total body aBMD and forearm BMC as well as increased rates of lumbar spine aBMD and forearm BA compared to the control females even in the cases they had lower bone mineral before the onset of training. According to Laing et al. (23), the tasks used in introductory gymnastic classes seem to be sufficient to cause gains in both bone mineral and size, especially spine and forearm.

\section{Cardiometabolic Health}

The cardiovascular disease development has been proved to begin as early as childhood (24) since risk factors like elevated cholesterol and blood pressure identified at that age follow children until they become adults (25). Observational, non-intervention studies provide some evidence for the positive effect of PA on cardiovascular risk factors prevention. In their longitudinal study Sääkslahti et al. (26) found that PA was associated with coronary heart disease risk factors (serum total cholesterol, HDL/total cholesterol ratio, triglycerides, cholesterol concentration, and systolic blood pressure) with differences between boys and girls. Specifically, in 6 years old girls high PA was negatively related to serum total cholesterol and positively to the HDL/total cholesterol ratio, while boys' PA correlated positively with serum HDL cholesterol concentration, HDL/total ratio and systolic blood pressure. In another longitudinal study (27), it was proved that PA of at least moderate intensity which sustained over three years was linked (even though weakly) to the improvement of children's metabolic health indicators (insulin resistance, triglycerides, cholesterol/ HDL ratio and blood pressure).

However, no study examining the effect of a PA intervention on preschoolers' cardiovascular health indicators has been identified.

\section{Motor Skill Development}

Preschool age is very crucial for human motor development, as during that specific period the fundamental movement skills, thought to be a prerequisite for both functioning in everyday life and participation in PA or sports later (28), are built up (5). Motor proficiency has been proved to be positively associated with PA (29). On the other hand, time spent in PA alone does not seem to be sufficient to cause positive changes in children's motor proficiency $(26,28)$, thus, oPA targeting at specific outcomes is on demand (30).

As motor skill development is considered to be the basic outcome of a movement programme, several researchers have investigated the results of various interventions of oPA. In four studies, music/movement programmes were implemented. Derri et al. (31) examined the influence of a music/movement programme on the quality of locomotion skills in 68 preschool children and found that 35 children who followed the 10 -week music/movement programme surpassed those of CG in gallop, hop, leaping, and skipping. Zachopoulou et al. (32) compared the effects of a music/movement and a physical education (PE) programme, that both lasted two months, on the dynamic balance and jumping in 90 4-6 years old children. The results indicated a significant improvement of the music/movement group proving that this specific kind of exercise can positively affect children's skills. Deli et al. (30) applied two 10-week intervention programmes (one music/movement and one movement) to two EGs of kindergarten children, while the CG of the study participated only in free play, so as to examine which programme was effective in the development of fundamental movement skills. According to their outcomes, both EGs significantly improved their running, hopping, leaping, horizontal jump, and skipping compared to CG. Similar were the findings of the study by Wang (33), in which the effect of a six week creative movement programme on the gross motor skills of $603-5$ years old children was investigated. The movement programme was implemented in EG twice a week, for 30 minutes each time, while CG participated in unstructured free play. Wang found significant differences between the two groups in their gross motor skills and specifically the locomotion ones.

Positive were also the findings of studies in which a PE programme was implemented. Iivonen et al. (34) examined the effect of a PE programme on 84 children's fundamental motor skills. The programme consisted of two 45 minute lessons that were conducted twice a week, for eight months and according to the results, the programme was found to cause the linear improvement of the standing broad jump of experimental girls and nonlinear improvement of the running speed of experimental boys. However, the programme was not effective in the development of children's manipulative skills.

Jones et al. (35) assessed the effects of a 20 weeks PE programme for preschool children. The participants of the study $(n=86)$ were randomly divided to CG and EG which participated 
in their typical day care curriculum or the intervention programme (20-min structured lesson, plus unstructured physical activities in the afternoons). The results displayed significant improvement of the EG's scores on the Test of Gross Motor Development - 2 (36). Also Reilly et al. (15) concluded that the enhanced PE programme they implemented for three 30-minute sessions every week over 24 weeks, had a significant positive effect on the EG's fundamental movement skills compared to those of CG that followed their typical curriculum.

In 2010, Ghaly (37) evaluated the effect of a movement programme consisting of 16 sessions with structured and unstructured movement patterns on 54 preschoolers' fundamental motor skills. After having applied the intervention, EG's TGMD - 2 (36) scores were significantly higher than those of the control ones. Kayapmar (38) intended to estimate the effectiveness of a movement education programme on the dynamic balance of children among 5-7 years of age. Of the 80 participants, 40 served as EG, taking part in the intervention programme consisting of fundamental movement skills, games and postures and lasted one hour, three days a week for three months. The rest of the children comprised CG that kept on to regular curriculum. Results revealed the significant improvement of the EG's dynamic balance.

Apart from PE and music/movement programmes, Psychomotor Education seems to be an effective approach to children's motor development. Zimmer et al. (39) applied a psychomotor training programme on 233 4-6 year old children, while 212 children continued their typical education curriculum. The results showed that EG presented greater improvement in their motor proficiency when compared to CG. Similarly positive were the findings of Kouli et al. (40) who implemented a psychomotor programme in a multicultural environment.

Finally, the effect of dance was investigated in one study (41), in which EG $(n=38)$ attended a bi-weekly introductory to Greek folk dances programme for 20 weeks, while CG $(n=28)$ did not enrol in any organized PA. Results showed that although both groups displayed improvement in their scores EG surpassed the control one in the post-test.

\section{Cognitive Development}

Preschool age is regarded as a sensitive period for the brain growth and it appears that the brain grows in size, complexity, and synaptic connections due to the quantity and quality of sensory experiences (42). Moreover, PA is considered a significant factor for early brain development and learning (43). Evidence for that belief is provided by research findings too. In the non-intervention, cross-sectional and longitudinal study of Niederer et al. (44) in 245 Swiss preschoolers, it was found that both higher levels of aerobic fitness and better motor skills were associated with better spatial working memory and attention.

Very few studies, however, have investigated the influence of oPA intervention on preschoolers' cognitive parameters. Zachopoulou et al. (45) implemented 20 PE lessons promoting creativity in 251 children aged $4-5$ and according to the results children improved both their creative fluency and their imagination.

Yazejian and Peisner-Feinberg (46) examined the influence of a classroom-based music/movement intervention on the language skills of 207 Head Start preschool children. EG received a 30 min. music/movement programme twice a week over 26 weeks, while
CG followed their typical curriculum. After the implementation of the intervention, children's receptive language ability, phonological awareness and communication skills were assessed. Results pinpointed that there were no significant differences between groups in language skills and phonological awareness; however, EG exhibited greater gains in communication skills.

\section{Psychosocial Health}

The positive effect of PA on psychosocial parameters in children and adolescents is theoretically supported (47). Nevertheless, the research on preschool children is limited. The earliest study found was that of Platzer (48), in which the effect of a perceptual - motor programme on the self-concept of 40 children, aged 35-72 months was examined. The children of EG received the perceptual - motor programme for 30 minutes, five days a week for 10 weeks, while children of CG continued with their regular curriculum and the results supported the effectiveness of the programme for children's self-concept.

Alpert et al. (49) evaluated the impact of aerobic exercise on 24 children aged 3-5 years. Twelve of the participants had 30 minutes of aerobic exercise, consisting of vigorous movements in playlike manner, everyday for eight weeks, while the rest participated only in free play. The results showed a significant improvement of the EG's agility and self-esteem, along with decrease in their heart rate during the aerobic measurement.

Lobo and Winsler (50) aimed at examining the effects of a creative dance/movement programme on the social competence of 40 Head Start programme children aged 39-62 months. Both EG and CG had a session of 35 minutes twice a week for eight weeks. EG engaged in a creative dance/movement programme, while CG simply played together with the available toys. Results revealed that EG presented significant improvement in their social competence and significant reduction in their behavioural problems compared to CG leading the authors to conclude that this programme may be an excellent means of improving at-risk preschoolers' behaviour.

Positive outcomes had yet another study with Head Start children (47), in which a classroom-based music and movement intervention was implemented 30 minutes twice a week, over 26 weeks on 130 Head Start children and their communication skills were compared to those of 77 children constituting CG. According to the results, the communication skills of EG were improved significantly more than the CG's ones, a fact that according to the authors may help preschool children to take advantage of learning opportunities at school.

\section{DISCUSSION}

The significant role of PA throughout the lifespan has been recognized around the world. However, whereas there is sufficient evidence about the benefits of PA in adulthood, the research findings become less and less as the population studied becomes younger. Taking into consideration the important role of preschool years for human's development, the scarcity of research evidence for that specific period sounds surprising. In the present study, an attempt was made to provide the existing evidence for the effect of oPA on preschool aged children's health. To our knowledge, this 
is the first review examining the aforementioned issue. Previous reviews concerning PA in preschool years focus on individual aspects of health, such as obesity $(51,52)$ and motor development (53) or examine how effective interventions are in increasing PA $(54,56)$. Only the review of Timmons et al. (6) examines all health indicators. Nonetheless, this study concerns only children aged up to four and it has to do with PA in general and not specifically with organized one.

Starting with adiposity, only four studies were detected whose results are conflicting ranging from significantly positive (17) to insignificant (14-16). With that evidence, it is difficult to decide how PA intervention could be effective in limiting weight gain or in reducing weight excess in preschool children. There are several possible explanations for those unclear findings. First of all, the choice of the measured outcomes may account for the failure of intervention accomplishment. Most studies reviewed used the BMI and/or other anthropometric measurements. In agreement with Monasta et al. (52) we are sceptical about the appropriateness of those indicators for preschool aged children. A better indicator might be the timing of adiposity rebound. Children who have their adiposity rebound earlier than at 5-6 years of age run a greater risk of suffering from obesity in adulthood (56).

Secondly, PA intensity should be taken into account, as it seems strongly associated with children's weight status (12). It is worth noticing that in studies in which oPA interventions were implemented in schoolchildren, those who maintained the highest heart rates during the intervention sessions displayed the greatest decrease in body fat (57). Finally, the multifactorial nature of BMI has to be discussed. Many variables, non-modifiable (e.g. age, family history for overweight) and modifiable ones (e.g. diet and PA) affect children's BMI. As a result, overweight and obesity require multi-faceted interventions including PA, inactivity, diet, schools, and families (58). However, according to WHO (59), since it is difficult for an obese child to lose weight through PA and healthy diet, the prevention of excess body weight in early ages is a strategy that can provide significant long-term benefits.

Regarding the impact of oPA on preschoolers' bone health, the findings of the two unique studies identified, reported in three papers $(20,22,23)$, are promising; on the other hand they are limited as for conclusions to be drawn. The main body of the relevant literature has focused on older children and research evidence has indicated that a high level of PA early in life is connected with high bone density in adulthood (60). Longitudinal research findings in preschoolers would provide valuable information about the influence of PA on young children's bone health indicators.

Although evidence for the role of oPA on young children's bones development is limited but promising, there is a total absence of studies examining the effect of PA intervention on cardiovascular health indicators in that specific age. In contrast to the above, numerous studies have looked into the positive effects of a movement programme on young children's motor development. Taken into consideration that developmentally appropriate movement programmes favour children's motor development (61), the important role of oPA against the negative influence of modern lifestyle on children's health is obvious.

At this point it is important to note the interrelationship between motor proficiency and PA. A high level of motor skills in early childhood forms the basis for an active lifestyle, making children's participation in PA easier and leading them to a more active adulthood (62). On the other hand, children with poor motor skills tend to be less physically active (29). In that way, they miss the chance of developing their motor skills and that results to a further and permanent avoidance of PA and adoption of a risky behaviour for their health lifestyle (63). Consequently, aiming at improving motor skills in preschool age may lead to greater participation in PA.

In regard to preschoolers' cognitive development only two intervention studies were traced with one revealing that PA lessons can improve children's creative fluency and imagination (45) and the other failing to prove that a music/movement programme can affect participants' language skills (46). Finally, the limited number of the four studies focusing on the psychosocial effects of PA provides promising findings for both children's self-concept and communicative skills.

From the above, it is apparent that further research into the relationship between oPA and health in preschool age is required so as conclusions for that important issue to be drawn. First, there is a need for the development of more valid, sensitive, reliable, and user-friendly tools for measuring PA in preschool children, which should measure the amount and pattern of activity and inactivity. Moreover, longitudinal studies are needed so as not only the short-term outcomes of PA on children's health but also the long-term ones to be assessed and the most efficient PA programmes for early years to be determined. Additionally, future research should seek to identify the causal pathways that lead to changes in PA and its effects on health; identify possible variable mediation; and explore the relationship between duration and intensity of interventions and changes in PA. Finally, the potential risks of PA for children's health have to be discussed. In the reviewed studies, no injuries caused by PA intervention were reported. However, the risk of injuries when a child replaces free play with competitive participation in sports should be underlined.

Even though the research evidence for the effects of oPA is in its infancy, the fact that most of that evidence was positive should be taken into consideration. Given the children's reduced spontaneous PA in current days, the responsibility of people engaged in preschool education and health to promote developmentally appropriate oPA becomes great. The USA Association for Sport and Physical Education' guidelines (64) suggest that preschoolers should participate in 60 minutes of oPA every day. Therefore, preschool and child care settings might play a critical role, given the large amount of time children spend there everyday. Recent research evidence (55) has revealed that those settings could offer opportunities for increasing PA and improving motor skills. In order to achieve both the aforementioned purposes PA classes should be integrated in preschoolers' daily school life. However, in most countries this is not the case. It is surprising that nowadays, when childhood obesity has become an epidemic, PA has not yet been an integral part of preschool curriculum. Nevertheless, the implementation of developmentally appropriate PA classes should be a main axis of effective policies for public health promotion. The other important axis should be the awareness of the "significant others" of young children's life so as to positively contribute to PA promotion. Family, neighbourhood, teachers, and society should support the engagement in PA. Among them, parents play a vital role (54). They should be informed and educated so as to encourage their children to participate in PA and be themselves physically active in order to act as role models for their offsprings. 


\section{CONCLUSIONS}

From the present review it becomes clear that, except for motor skills, the current information about the effect of oPA on preschoolers' health is deficient. Current research provides encouraging results, but questions about the kind, intensity, amount or frequency of PA required so as children's health to be enhanced still remain. The content of the implemented interventions ranged from PA lessons to dance and creative movement, while the sessions frequency varied. Moreover, although the intensity of PA is known to affect health indicators, it was not assessed in the studies reviewed, impeding in that way drawing conclusions about the adequate level of intensity in order to achieve optimal effects.

There is a long way ahead, so as sound evidence about the best PA practices for health promotion in preschool years to be identified. However, that specific period is too important for human development to remain unexploited or even be lost. Investing in developmentally appropriate PA programmes in early years will contribute to better life quality of nowadays children and future citizens of this world.

\section{Conflict of Interests}

None declared

\section{REFERENCES}

1. Lobstein T, Baur L, Uauy R; IASO International Obesity TaskForce. Obesity in children and young people: a crisis in public health. Obes Rev. 2004 May;5 Suppl 1:4-104.

2. World Health Organization. Obesity and overweight. Fact Sheet No. 3. Geneva: WHO; 2011.

3. Hinkley T, Crawford D, Salmon J, Okely AD, Hesketh K. Preschool children and physical activity: a review of correlates. Am J Prev Med. 2008 May;34(5):435-441.

4. Oliver M, Schofield GM, Kolt GS. Physical activity in preschoolers: understanding prevalence and measurement issues. Sports Med. 2007;37(12):1045-70.

5. Gallahue D, Cleland-Donnelly F. Developmental physical education for all children. 4th ed. Champaign (US): Human Kinetics; 2003.

6. Timmons BW, LeBlanc AG, Carson V, Connor Gorber S, Dillman C, Janssen I, et al. Systematic review of physical activity and health in the early years (aged 0-4 years). Appl Physiol Nutr Metab. 2012 Aug;37(4):773-92.

7. Reilly JJ, Armstrong J, Dorosty AR, Emmett PM, Ness A, Rogers I, et al. Early life risk factors for obesity in childhood: cohort study. BMJ. 2005 Jun 11;330(7504):1357.

8. Tremblay MS, LeBlanc AG, Carson V, Choquette L, Connor Gorber S, Dillman C, et al. Canadian physical activity guidelines for the early years (aged 0-4 years). Appl Physiol Nutr Metab. 2012 Apr;37(2):345-69. (In French.)

9. Thorleifsson G, Walters GB, Gudbjartsson DF, Steinthorsdottir V, Sulem $\mathrm{P}$, Helgadottir A, et al. Genome-wide association yields new sequence variants at seven loci that associate with measures of obesity. Nat Genet. 2009 Jan;41(1):18-24.

10. Loos RJ, Rankinen T. Gene-diet interactions on body weight changes. J Am Diet Assoc. 2005 May;105(5 Suppl 1):S29-34.

11. Klesges RC, Klesges LM, Eck LH, Shelton ML. A longitudinal analysis of accelerated weight gain in preschool children. Pediatrics. 1995 Jan;95(1):126-30.

12. Vale SM, Santos RM, da Cruz Soares-Miranda LM, Moreira CM, Ruiz JR, Mota JA. Objectively measured physical activity and body mass index in preschool children. Int J Pediatr. 2010;2010. pii: 479439.

13. Moore LL, Gao D, Bradlee ML, Cupples LA, Sundarajan-Ramamurti A, Proctor $\mathrm{MH}$, et al. Does early physical activity predict body fat change throughout childhood? Prev Med. 2003 Jul;37(1):10-7.

14. Mo-suwan L, Pongprapai S, Junjana C, Puetpaiboon A. Effects of a controlled trial of a school-based exercise program on the obesity indexes of preschool children. Am J Clin Nutr. 1998 Nov;68(5):1006-11.
15. Reilly JJ, Kelly L, Montgomery C, Williamson A, Fisher A, McColl $\mathrm{JH}$, et al. Physical activity to prevent obesity in young children: cluster randomised controlled trial. BMJ. 2006 Nov 18;333(7577):1041.

16. Fitzgibbon ML, Stolley MR, Schiffer L, Van Horn L, KauferChristoffel K, Dyer A. Hip - Hop to health Jr. for Latino preschool children. Obesity (Silver Spring). 2006 Sep;14(9):1616-25.

17. Fitzgibbon ML, Stolley MR, Schiffer L, Van Horn L, KauferChristoffel K, Dyer A. Two-year follow-up results for hip-hop to health Jr.: a randomized controlled trial for overweight prevention in preschool minority children. J Pediatr. 2005 May;146(5):618-25.

18. Karlsson MK, Nordqvist A, Karlsson C. Sustainability of exerciseinduced increases in bone density and skeletal structure. Food Nutr Res. 2008;52:502-8.

19. Marcus R. The nature of osteoporosis. In: Marcus R, Feldman D, Kelsey J, eds. Osteoporosis. 2nd ed. San Diego: Academic Press; 2001. p. 3-18.

20. Specker B, Binkley T. Randomized trial of physical activity and calcium supplementation on bone mineral content in 3- to 5-year-old children. J Bone Miner Res. 2003 May;18(5):885-92.

21. Specker BL, Johannsen N, Binkley T, Finn K. Total body bone mineral content and tibial cortical bone measures in preschool children. J Bone Miner Res. 2001 Dec;16(12):2298-305.

22. Specker B, Binkley T, Fahrenwald N. Increased periosteal circumference remains present 12 months after an exercise intervention in preschool children. Bone. 2004 Dec;35(6):1383-8.

23. Laing EM, Wilson AR, Modlesky CM, O'Connor PJ, Hall DB, Lewis $\mathrm{RD}$. Initial years of recreational artistic gymnastics training improves lumbar spine bone mineral accrual in 4- to 8-year-old females. J Bone Miner Res. 2005 Mar;20(3):509-19.

24. McGill HC Jr, McMahan CA, Herderick EE, Malcom GT, Tracy RE, Strong JP. Origin of atherosclerosis in childhood and adolescence. Am J Clin Nutr. 2000 Nov;72(5 Suppl):1307S-1315S.

25. Nicklas TA, von Duvillard SP, Berenson GS. Tracking of serum lipids and lipoproteins from childhood to dyslipidemia in adults: the Bogalusa Heart Study Int J Sports Med. 2002 May;23 Suppl 1:S39-43.

26. Sääkslahti A, Numminen P, Varstala V, Helenius H, Tammi A, Viikari $\mathrm{J}$, et al. Physical activity as a preventive measure for coronary heart disease risk factors in early childhood. Scand J Med Sci Sports. 2004 Jun;14(3):143-9.

27. Metcalf BS, Voss LD, Hosking J, Jeffery AN, Wilkin TJ. Physical activity at the government-recommended level and obesity-related health outcomes: a longitudinal study (Early Bird 37). Arch Dis Child. 2008 Sep;93(9):772-7.

28. Fisher A, Reilly JJ, Kelly LA, Montgomery C, Williamson A, Paton JY, et al. Fundamental movement skills and habitual physical activity in young children. Med Sci Sports Exerc. 2005 Apr;37(4):684-8.

29. Williams HG, Pfeiffer KA, O'Neill JR, Dowda M, McIver KL, Brown $\mathrm{WH}$, et al. Motor skill performance and physical activity in preschool children. Obesity (Silver Spring). 2008 Jun;16(6):1421-6.

30. Deli E, Bakle I, Zachopoulou E. Implementing intervention movement programs for kindergarten children. J Early Child Res. 2006 Feb;4(1):5-18.

31. Derri V, Tsapakidou A, Zachopoulou E, Kioumourtzoglou E. Effect of a music and movement program on development of locomotor skills by children 4-6 years of age. Eur J Phys Educ. 2001;6(1):16-25.

32. Zachopoulou E, Tsapakidou A, Derri V. The effects of a developmentally appropriate music and movement program on motor performance. Early Child Res Q. 2004 4th Quarter;19(4):631-42.

33. Wang JH. A study on gross motor skills of preschool children. J Res Child Educ. 2004;19(1): 32-43.

34. Iivonen S, Sääkslahti A, Nissinen K. The development of fundamental motor skills of four- to five-year-old preschool children and the effects of a preschool physical education curriculum. Early Child Dev Care. 2011;181(3):335-43.

35. Jones RA, Riethmuller A, Hesketh K, Trezise J, Batterham M, Okely AD. Promoting fundamental movement skill development and physical activity in early childhood settings: a cluster randomized controlled trial. Pediatr Exerc Sci. 2011 Nov;23(4):600-15.

36. Ulrich DA. Test of gross motor development. Examiner's manual. 2nd ed. Austin: Pro-Ed; 2000.

37. Ghaly WA. The effect of movement education program by using movement pattern to develop fundamental motor skills for children pre-school. World J Sport Sci. 2010;3 Suppl:461-91.

38. Kayapmar FÇ. The Effect of the movement education on the dynamic balance skills of pre-school children. World Appl Sci J. 2011;12(6):871-6.

39. Zimmer R, Christoforidis C, Xanthi P, Aggeloussis N, Kambas A. The effects of a psychomotor training program on motor proficiency of Greek preschoolers. Eur Psychomotor J. 2008;1(2):3-9. 
40. Kouli O, Avloniti A, Venetsanou F, Giannakidou D, Gazi S, Kambas A. The effect of a psychomotor training program on the motor proficiency of preschool children in a multicultural environment. Eur Psychomotor J. 2010;3(1):31-6.

41. Venetsanou F, Kambas A. How can a traditional Greek dances programme affect the motor proficiency of pre-school children? Res Dance Educ. 2004;5(2):127-38.

42. Singer W. Development and plasticity of cortical processing architectures. Science. 1995 Nov 3;270(5237):758-64.

43. National Association for Sport \& Physical Education. Active start: statement of physical activity guidelines for children birth to give years. Reston: National Association for Sport and Physical Education; 2002.

44. Niederer I, Kriemler S, Gut J, Hartmann T, Schindler C, Barral J, et al. Relationship of aerobic fitness and motor skills with memory and attention in preschoolers (Ballabeina): a cross-sectional and longitudinal study. BMC Pediatr. 2011 May 11;11:34.

45. Zachopoulou E, Trevlas E, Konstadinidou E; Archimedes Project Research Group. The design and implementation of a physical education program to promote children's creativity in the early years. Int J Early Years Educ. 2006 Oct;14(3):279-94.

46. Yazejian N, Peisner-Feinberg ES. Effects of a preschool music and movement curriculum on children's language skills, NHSA dialog: a research-to-practice. J Early Child Field. 2009;12(4):327-41.

47. Biddle SJ. Children, exercise and mental health. Int J Sport Psychol. 1993;24(2):200-16.

48. Platzer WS. Effect of perceptual motor training on gross-motor skill and self-concept of young children. Am J Occup Ther. 1976 Aug;30(7):422-8.

49. Alpert B, Field T, Goldstein S, Perry S. Aerobics enhances cardiovascular fitness and agility in preschoolers. Health Psychol. 1990;9(1):48-56.

50. Lobo YB, Winsler A. The effects of a creative dance and movement program on the social competence of Head Start preschoolers. Soc Dev. 2006 Aug;15(3):501-19.

51. Hodges EA, Smith C, Tidwell S, Berry D. Promoting physical activity in preschoolers to prevent obesity: a review of the literature. J Pediatr Nurs. 2013 Jan;28(1):3-19.

52. Monasta L, Batty GD, Macaluso A, Ronfani L, Lutje V, Bavcar A, et al. Interventions for the prevention of overweight and obesity in preschool children: a systematic review of randomized controlled trials. Obes Rev. 2011 May;12(5):e107-18.

53. Riethmuller AM, Jones RA, Okely AD. Efficacy of interventions to improve motor development in young children: a systematic review. Pediatrics. 2009 Oct;124(4):e782-92.
54. Goldfield GS, Harvey A, Grattan K, Adamo KB. Physical activity promotion in the preschool years: a critical period to intervene. Int J Environ Res Public Health. 2012 Apr;9(4):1326-42.

55. Gordon ES, Tucker P, Burke SM, Carron AV. Effectiveness of physical activity interventions for preschoolers: a meta-analysis. Res Q Exerc Sport. 2013 Sep;84(3):287-94.

56. Whitaker RC, Pepe MS, Wright JA, Seidel KD, Dietz WH. Early adiposity rebound and the risk of adult obesity. Pediatrics. 1998 Mar;101(3):E5.

57. Gutin B, Yin Z, Johnson M, Barbeau P. Preliminary findings of the effect of a 3-year after-school physical activity intervention on fitness and body fat: the Medical College of Georgia Fitkid Project. Int J Pediatr Obes. 2008;3 Suppl 1:3-9.

58. Goran MI, Reynolds KD, Lindquist CH. Role of physical activity in the prevention of obesity in children. Int J Obes Relat Metab Disord. 1999 Apr;23 Suppl 3:S18-33.

59. Population-based prevention strategies for childhood obesity: report of a WHO forum and technical meeting; 2010 Dec 15-17; Geneva: WHO; 2010 .

60. Välimäki MJ, Kärkkäinen M, Lamberg-Allardt C, Laitinen K, Alhava E, Heikkinen J, et al. Exercise, smoking, and calcium intake during adolescence and early adulthood as determinants of peak bone mass. Cardiovascular Risk in Young Finns Study Group. BMJ. 1994 Jul 23;309(6949):230-5

61. Venetsanou F, Kambas A. Environmental factors affecting preschoolers' motor development. Early Child Educ J. 2010;37(4):319-27.

62. Stodden DF, Goodway JD, Langendorfer SJ, Roberton MA, Rudisil ME, Garcia C, et al. A developmental perspective on the role of motor skill competence in physical activity: an emergent relationship. Quest. 2008;60(2):290-306

63. Zimmer R. Lack of exercise - too much weight. Frühe Kindheit. 2003;4:15-7. (In German.)

64. SHAPE America - Society of Health and Physical Educators. Active start: a statement of physical activity guidelines for children from birth to age 5. 2nd ed. Oxon Hill: AAHPERD Publications; 2009.

Received May 27, 2014

Accepted in revised form March 29, 2015 